\title{
THE IMPLICATIONS OF CLIMATE CHANGE FOR AFRICA'S ECONOMIC DEVELOPMENT
}

\author{
Pinky Lalthapersad-Pillay \\ University of South Africa \\ lathp@unisa.ac.za.
}

Received: July 2012

\author{
Eric Udjo+ \\ University of South Africa \\ udjoe@unisa.ac.za
}

Accepted: November 2013

\begin{abstract}
Studies confirm that developing countries could be hardest hit by climate change given that they have to contend with extreme poverty levels and harsh geographic conditions. Even Africa will not escape the adversity that climate change will engender. Climate change could impact negatively on water resources, land quality, forestation and ecosystems, which may threaten livelihoods and food security, making it foremost a development issue. Existent socio-economic conditions in developing countries place them at greater risk to climate change as these inequities are likely to be reinforced by climate change, thereby jeopardising their future economic development. The results of the analysis based on the calculation of an overall index comprising four proxy variables, showed that eleven African countries are high risk countries whose future economic development may be impeded by climate change. Adaptation, economic diversification, mitigation, climate-smart polices within the framework of development policy are pertinent policy options.
\end{abstract}

Keywords

Climate change, economic development, Africa, poverty, food security, policy

\#Prof P Lalthapersad-Pillay is professor in the Department of Economics, University of South Africa, South Africa.

+Prof $\varepsilon \mathbf{O}$ Udjo is Research Director in the Bureau of Market Research, University of South Africa, South Africa. 


\section{INTRODUCTION}

The aim of the article is to show how countries' current development challenges place them at greater risk of the effects of climate change, as these inequities are likely to be exacerbated by climate change, thereby jeopardising their future economic development. Studies show that climate change would trigger erratic weather events such as droughts, floods, rising sea levels and rising temperatures, all off which will take their toll on developing countries (World Bank, 2010; Tol, 2010; Sarkar, 2012). Such weather extremes could affect agricultural production, the availability of and access to water resources, livelihood patterns, food security and the health burden of countries. It has been argued that climate change extends beyond environmental policy, making it primarily a development issue and a key adjunct of sustainable development (Sarkar, 2012). Developing countries already face huge challenges with their present climate, and are still disadvantaged in terms of their economic development, a situation that could be compounded by climate change and cause them to lag behind even further. Even though African countries contribute the least to GHG emission (only $4 \%$ ), the continent's geographical fragility and its reliance on climate-sensitive resources make it vulnerable to the effects of climate change (UNECA, 2009).

Several studies have indicated that climate change would impact negatively on the economic development of African countries, but these studies do not specify which countries would be worst affected, and it cannot be assumed that all countries will be equally affected (Adger 2006; Galor \& Weil, 1999; Tang, Petrie \& Rao, 2009; Tol, 2010). It is likely that certain African countries are at greater risk than others. A simple analysis showing risk levels to climate change is important. The article begins by reviewing the possible effects of climate change in developing countries and in Africa as a whole in terms of economic costs, food security, the spread of diseases and the poor's plight. Secondly, it analyses how current socio-economic conditions in certain African countries make them more vulnerable to the effects of climate change. Thirdly, it discusses the policy options that could mitigate the effects of climate change. The results of the analysis, which is based on a calculation of an overall index comprising four proxy variables, showed that 11 African countries are high-risk countries whose future economic development may be impeded by climate change.

\section{EFFECTS OF CLIMATE CHANGE IN DEVELOPING COUNTRIES}

Estimates imply that even a $2^{0} \mathrm{C}$ warming above pre-industrial temperatures (which is the minimum the world is likely to experience) will give rise to two eventualities. Firstly GDP in Africa and Asia will fall by 4 to $5 \%$ as opposed to a $1 \%$ GDP loss in high-income countries; and, secondly, it will unleash variations in weather patterns that will put between 100 million and 400 million people at risk of hunger, and place between 1 billion to 2 billion people at risk of not having enough water to meet their needs (Niasse, Afoud \& Sygna, 2004). Natural disasters also have economic consequences, and in developing countries $90 \%$ of economic losses due to storms, floods and droughts are borne by households, businesses and governments. It is estimated that developing countries will have to absorb most of the damages arising from natural disasters - that is, about $75 \%$ to $80 \%$ of such damages (World Bank, 2010).

The literature on the impact of climate change recognises the existence of differing degrees of vulnerabilities across communities, groups of people, sectors, regions and countries. 0'Brien, Sygna and Haugen (2004) single out the elderly as one vulnerable group that could be severely 
affected by climate adversity. Developing countries, SIDS (small island developing states), people living in arid and semi-arid areas, areas that have water scarcity or that are subject to flooding, and countries where livelihood patterns are fundamentally reliant on climate-sensitive sectors such agriculture, water resources, forestry, fisheries are deemed to be high-risk ones. These contrasts of vulnerabilities arise since there will be uneven changes in the temperature and rainfall globally. Climate change will also have different effects in rich and poor countries, and the former have the necessary means plus a robust population that is well-educated and healthy and that will adapt easily. The latter group of countries are disadvantaged on all three fronts and will not be able to cope effectively (Sarkar, 2012; Shackleton \& Shackleton, 2012).

How developing countries will fare with regard to climate change has to be contextualised in terms of their present development circumstances, as they are saddled with widespread inequalities and major backlogs. Statistics show that as much as a quarter of the population in developing countries live on less than a dollar a day, one billion do not have access to clean drinking water, 1.6 billion are without electricity, 3 billion lack adequate sanitation services and a quarter of all children are malnourished (World Bank, 2010). The existing poverty in lowincome countries is the crucial factor that underpins the negative consequences that climate change will trigger (Tol, 2010). These realities imply that developing countries still have unmet development priorities, the attainment of which will be more difficult under conditions of climate variability. It is estimated that by 2050 the global population is likely to total 9 billion, and developing countries will have an additional 2.5 billion people, which will place further stresses on natural resources (World Bank, 2010).

The reasons why the impact of climate change will be worse for developing countries is anchored in some key features of these countries. Most of them, and especially those in the tropical zones, are already predisposed to harsh climatic conditions that disadvantage their economic growth and economic development and that have shaped their agricultural sectors. They also lack the necessary resources and institutional capacity to implement adaptation measures (Adger 2006; Tol 2010). Their heavy reliance on climate-sensitive resources also counts against them (Eriksen, O'Brien \& Losentrater, 2008). Under these conditions, climate change could erode resources away from development initiatives and reduce GDP (World Bank, 2010).

\section{THE \&CONOMIC CONTEXT OF CLIMATE CHANGE}

Climate change was initially viewed in terms of its import for the natural sciences, but it has economic implications for both the developed and developing countries, particularly the economic development of the latter group of countries. The United Nations Framework Convention on Climate Change (UNFCCC) of 1994 and the Kyoto Protocol in 1997 confirmed the connection between environment and development, making it in essence an economic issue with wide-ranging socio-economic and development impacts. Sarkar (2012) describes climate change as a development problem that is rooted in sustainable development policy and is something that will gravely encumber poorer countries. Several studies maintain that climate change would translate into lower annual rates of economic growth and that an inability to adapt would further depress economic growth rates (Tol, 2010). Del, Jones and Olken (2008) contend that climate change would reduce the annual growth rates of poor countries by 0.6 to $2.9 \%$. Other studies focus on the effect that the outbreak of diseases such as malaria and diarrhoea will have on economic growth (Galor \& Weil, 1999; Tang et al., 2009; Shackleton \& 
Shackleton, 2012). Yet other studies consider how the conflict that will be sparked by the scarcity of natural resources will affect economic growth.

Climate change is likely to induce migration and a relocation of people mainly from rural areas to cities, which may put added pressure on urban infrastructure. There could also be migration to areas where water resources are more plentiful in an attempt to improve crop yields, which could mean greater encroachment on ecosystems (Brown \& Crawford, 2007). However, some impacts of climate change have been not been ascertained - for example, the consequences of higher wind speeds and less sea ice, and the impact of climate change on tourism. Impact estimates indicate that sub-Saharan Africa could lose a quarter of its income (Tol, 2010). Clemens (2009) estimates that economic losses due to climate change will amount to $14 \%$ of GDP if adaptation measures are not implemented. Under such a scenario, resources would be reallocated away from development projects to fund short-term emergency needs (FA0, 2010).

\section{4. \&FFECTS OF CLIMATE CHANGE IN AFRICA}

The question that must be asked is how Africa will fare with regard to climate change. African countries contribute the least to GHG emissions (only 4\%), but the continent's geographic fragility, livelihood patterns, financial and institutional inadequacies and modest economic development amplify its vulnerability to climate change adversity (UNECA, 2009). In subSaharan Africa (excluding South Africa), agriculture both produces the food that people consume and is also the main source of income for almost two-thirds of the working population (ILO, 2008). The anticipated losses in GDP would be caused by a slowing down of economic activity in the agricultural sector. Falling agricultural yields due to climate change will destabilise the basic livelihood of a huge proportion of people and render them susceptible to food insecurity (FA0, 2010).

The FAO (2008) sees food security as compromising four elements which will be enfeebled by climate change: food availability, food accessibility, food utilisation and food system stability (namely, affordability). Food availability is determined by physical location and the occurrence of moderate warming (an increase of $1^{\circ} \mathrm{C}$ to $3^{\circ} \mathrm{C}$ ) in the tropical and dry regions of Africa will adversely affect cereal yields, with maize output likely to fall by 6.9\% (Brown \& Crawford, 2007; FA0, 2010). Food accessibility entails modifications in the allocation of food in both markets and at household level (Medany, Niang-Diop, Nyong, Tabo \& Vogel, 2006). Food utilisation encompasses the nutritional value and the safety of food - and of concern here is the new diseases and pests that are likely to attack plants and animals (FA0, 2010). Food system stability is reflective of the state of agriculture, which in Africa is thwarted by low investment, reliance on rain-fed conditions, land degradation and very low levels of irrigation, namely, only $16 \%$ (FA0, 2003).

Climate change also has gender implications for the women and children in Africa, as women in rural areas see to the nutritional needs of the family and bear a disproportionate share of the food security burden (FAO, 2003). Women also participate in subsistence agriculture and are reliant on climate-sensitive resources, especially rain-fed agriculture (IFAD, 2009). Women subsistence farmers in Africa encounter a number of hurdles: they tend to cultivate marginal lands, and have limited access to land, labour, water, equipment, technology and information. They are also hindered by institutional impediments such as customary laws that forbid them from inheriting or owning land, as well as little or no access to credit and agricultural extension services (Brody, Demetriades \& Esplen, 2008). The depletion of natural resources and reduced 
agricultural yields could intensify women's workload, mainly the collection of firewood (World Bank, 2010; FAO, 2010). Children too could be affected due to greater search time to locate water, fuel, wood and fodder, which may ultimately affect their schooling (FAO, 2010).

\section{HEALTH OUTLOOK, SCHOOLING AND COPING BY HOUSEHOLDS}

Climate change is also likely to have consequences for the health outlook of people and school attendance. Given the labour-intensity of agriculture, the ill-health that derives from extreme climatic conditions may impede work effort, reduce agricultural output and undermine food sufficiency (Confalonieri et al., 2007). Climate change is likely to have health complications, especially among the poor. The inability to secure food will hasten the onset of malnutrition, thereby making people more prone to illness. It is estimated that there will be an additional 150 000 deaths a year due to climate change. Adverse climatic conditions caused a loss of 5.5 million disability life years in $2000,84 \%$ of them in sub-Saharan Africa, East and south Asia (Campbell-Lendrum, Corvalan \& Pruss-Ustan, 2003). The disease burden could escalate through a rise in temperature that could see a higher incidence of diarrhoeal diseases and vector-borne illnesses (especially malaria), which historically poses a huge public health challenge in Africa (FA0, 2010). Currently malaria cripples countries in tropics and causes almost 1 million deaths, mostly of children.

Climate change is estimated to expose 90 million more people (a 14\% increase) to the disease by 2030 in Africa alone. The incidence of diarrhoeal diseases from climate change is estimated to increase by up to $5 \%$ by 2020 in countries with per capita incomes below $\$ 600$ (Confalonieri et al., 2007). Children are most prone to environmental contamination-related diseases such as diarrhoea, which is the major contributor to child mortality in developing countries. Reducing child mortality is also an MDG goal, and requires urgent attention. Drought, which is likely to increase, especially in the Sahel region, could result in more cases of meningitis. Dengue could become more widespread geographically, which could put almost $60 \%$ of the population (up from 30\%) at risk by 2070 (World Bank, 2010).

\section{6. \&FFECTS OF CLIMATE CHANGE ON THE POOR}

It is widely documented that poor households will grapple the most with climate change, and will suffer a loss of livelihood (World Bank, 2010; Shackleton \& Shackleton, 2012). It would disadvantage the poor in two ways, given the link between reduced agricultural output and the incidence of poverty from changes in GDP growth due to climate change. Firstly, research shows that a $1 \%$ gain in agricultural GDP growth in developing countries elevates the consumption of the poorest third of the population by 4 to $6 \%$. Conversely, a decrease in GDP is likely to have a similar restraining effect on consumption patterns (Collier, Conway \& Venebles, 2008). Secondly, the degradation of natural resources would have the gravest repercussions for the poor, as close to $70 \%$ of the world's poor people live in rural areas and the poor also utilise natural resources most extensively (World Bank, 2010).

Other incapacities, such as the inability to bear physical and financial risk or undertake longterm adaptation efforts due to a lack of entitlements, the utilisation of unproductive assets and limited or no participation in decision-making processes, will make the poor more vulnerable (World Bank, 2010). Poor households will have to endure a loss of both human and physical 
capital. Empirical evidence on poverty traps (defined as consumption permanently below a given threshold) is not clear-cut, but it does show that both the recovery of physical assets and the growth of human capital are delayed after catastrophic events and require long recovery periods (World Bank, 2010; Skoufias, Vinha \& Conroy, 2011). Research shows that weather calamities such as the occurrence of Hurricane Mitch in Honduras in 1998 wrought havoc on poor households, as they lost 15 to $20 \%$ of their assets, their resumption of purchasing of assets was very slow and their destitution was long term. On the other hand, rich households fared much better and lost only $3 \%$ of their assets (World Bank, 2010).

\section{OTHER IMPACTS FROM RECENT CLIMATIC EVENTS}

Researchers observing the recovery process following Hurricane Mitch in 1998 found that the pace of recovery differed according to household headship type, the length of the recovery period, access to new accommodation and confinement to disaster shelters, all of which was shorter for male-headed households than for female-headed ones (World Bank, 2001; Carter, Little, Mogues \& Negatu, 2007). In Ethiopia, research shows that low levels of rainfall indirectly affected consumption, which remained low four to five years down the line (Dercon, 2004). In Brazil, drought activity caused rural wages to fall substantially in the short term, with the wages of affected workers reaching the level of their peers only five years on (Mueller \& Osgood, 2007). Studies have examined how climate shocks affected people's health and educational acquirements. Research by Jensen (2000) on Cote d'Ivoire, which analysed the link between rainfall patterns and investments in children's education, showed that in regions experiencing greater than usual weather variability, school enrolment rates fell by $20 \%$ for both boys and girls. Research by Alderman, Hoddinott and Kinsey (2006) showed that individuals who endured drought and civil strife in Zimbabwe during early childhood (between 12 and 24 years) experienced a loss of height of three to four centimetres, close to one year fewer of schooling and nearly six months' delay in starting school. The estimated effect on lifetime earnings was $14 \%$, which is quite substantial from the poor's perspective.

\section{SOME EVIDENCE OF ATMOSPHERIC WARMING}

The Third Assessment Report of the Intergovernmental Panel on Climate Change (IPCC) concluded that, globally, climate change has already taken hold, as demonstrated by the rise in average land and sea surface temperature by $0.6^{\circ} \mathrm{C} \pm 0.20^{\circ} \mathrm{C}$ between the mid-nineteenth century and 1976. Warming has been recorded in all continents, with the highest temperature changes being experienced at middle and high latitudes in the northern hemisphere. Rainfall patterns have changed, with arid and semi-arid regions becoming drier and mid-to-high latitudes getting wetter due to more frequent and heavy spells of rainfall (Sarkar, 2012). Likewise, Africa has seen general increases in its temperature since the industrial era, and its rainfall patterns have become more variable in the last century. Mean annual rainfall has decreased in West Africa since the 1960s, while southern and eastern Africa has become more drought-prone. One-third of Africans now live in drought-prone areas, especially in the Sahel, around the horn of Africa and in southern Africa (PACJA, 2009). Sub-Saharan Africa has experienced lower rainfall patterns accompanied by shrinkage of most natural resources. Lake Chad's surface area has been reduced from $20000 \mathrm{~km}^{2}$ before the $1970 \mathrm{~s}$ to $7000 \mathrm{~km}^{2}$ by the 
1990 s, causing it to become shallower and split into two parts, with water being found only in the southern parts (Niasse et al., 2004).

\section{AN ANALYSIS OF CLIMATE CHANGE AND RISK}

\subsection{Data and methods}

Although most of Africa will feel the adverse effects of climate change, certain African countries could be at greater risk given their current socio-economic conditions. The study uses a number of proxy variables to determine a country's vulnerability to the adverse effects of climate change based on their existent socio-economic conditions. To support this assertion, data on proxy development indicators was sourced. Data on the indicators was obtained from the World Bank (2010) and Food and Agricultural Organization (FAO) (2008) reports. The values of the relevant indicators for this study from this data were obtained for 46 of the 53 countries. These values were captured in an Excel spreadsheet and exported to SPSS. All programming, including data transformation and statistical analyses, was done in SPSS.

Although the data pertains to different years and is not directly comparable, it is indicative of a country's present development challenges. These inequities will place such countries at greater risk to the effects of climate change, as they are likely to be reinforced by climate-change impacts. The first proxy variable, the Global Hunger Index (GHI), is an index of the level of hunger in countries, and its value ranges from zero to thirty, with a value of less than five signifying low levels of hunger. Hunger becomes more severe as the index value rises. Studies show that food insecurity and hunger could worsen with climate change. The second proxy variable, the proportion of population living on less than $\$ 1$ a day, is a headcount measure of poverty in a country. Due to the threat to people's livelihoods, the proportion of those in poverty could rise substantially. The old measure of headcount poverty rather than the newer yardstick of $\$ 1.25$ was used, because data for all countries was not available.

The third proxy variable, the value added to GDP by agriculture, reflects how climate change could lower GDP, economic growth, and trade volumes, which is likely to reduce funds for poverty alleviation and adaptation efforts. It also affects food security at a country level. The fourth proxy variable is the proportion of malnourished people in a population, which is an indicator of nutritional status. Inadequate nutritional intake may cause protein deficiencies. According to Matorell and Ho (1984), socio-economic factors (especially poverty) are important determinants of malnutrition in developing countries. The fifth proxy variable, the proportion of the population living in rural areas, is a crude measure of the size of the population whose livelihoods depend on climate-sensitive ecological resources and which may be the catalyst to poverty and destitution, with the proportion of rural residency varying directly with greater exposure to climate change.

To determine whether countries are characterised by a significant number of proxy variables, countries were firstly ranked across a continuum of proxy variables. Secondly, to obtain a clearer picture, a more refined statistical method was used to examine the data whereby a composite index for four proxy variables was computed. The composite index, which takes a value between 0 and 1 or between 0 and $100 \%$, was computed using a similar approach as in the calculation of the Human Development Index (Anand \& Sen, 1994). The composite index was based on the following four variables: the proportion of population living on less than $\$ 1$ a day, the value added to GDP by agriculture, the proportion of malnourished people in a population and the proportion of the 
population living in rural areas. For each of the four variables, the index for each country was first computed as:

$$
\text { Clndex }=(\text { Cvalue }- \text { Cminimum }) /(\text { Cmaximum }- \text { Cminimum })
$$

where CIndex is the country's index for a particular variable, Cvalue is the country's actual value of the indicator variable for the country, Cminimum is the minimum value of the indicator in the frequency distribution of the indicator variable for all countries and Cmaximum is the maximum value of the indicator in the frequency distribution of the indicator variable for all countries. The index was computed for 44 African countries for which complete data on the relevant variables was available. Secondly, the composite index for each country was computed as:

$$
\text { Overallindex }=0.25(C \operatorname{lndex} 1)+0.25(C \ln \operatorname{lex} 2)+0.25(\text { Cindex } 3)+0.25(C \operatorname{lndex} 4)
$$

where Overallindex is the uniformly weighted sum of the four indices (overall index), with each index contributing 0.25 or $25 \%$. Finally, using the quartile values of the distribution of the Overallindex, countries were categorised as low risk (composite index between 0 and 0.3124 or $0 \%$ and $31.24 \%$ ), medium risk (composite index between 0.3125 and 0.6601 or $31.25 \%$ and $66.01 \%$ ) and high risk (composite index between 0.6602 and 1.0 or $66.02 \%$ and $100 \%$ ). Note that $\mathrm{GHI}$ was not included in the composite index, since $\mathrm{GHI}$ itself is a composite index.

\subsection{Results and discussion}

The ranking of the countries is shown in TABLE l. FIGURE l summarises the values relative to a central point of zero for each of the countries' indicators shown TABLE 1 . For the countries in FIGURE $1, G H I$ is the global hunger index, Pop\$ 1 is the percent of the population living on less than $\$ 1$ la day, Agric\%GDP is the value added as a percentage to GDP by agriculture, Pcctunder is the percentage of the population that is undernourished, and Pcrural is the percentage of the population living in rural areas. As can be seen from the graph in FIGURE 1, no definite picture emerges with regard to which countries appear at the upper limits for all proxy variables, which would indicate their greater risk to climate change. For example, as can be seen in TABLE 1, although Egypt has a low GHI level (4.9) it is one of the two countries with the highest proportion of rural population. Although Ghana has the highest proportion of the population living on less than $\$ 1$ a day, it has a lower proportion of undernourished population compared to countries such as Cape Verde, Lesotho and Uganda. This makes country comparisons difficult. The only noticeable trend that the TABLE 1 and FIGURE 1 portray is that certain countries such as Eritrea, Sierra Leone, Chad, Ethiopia, Madagascar, Comoros, Zambia, Rwanda, Mozambique, Liberia, Guinea-Bissau, Togo, Tanzania and Mali lie at the upper end of certain proxy variables. 


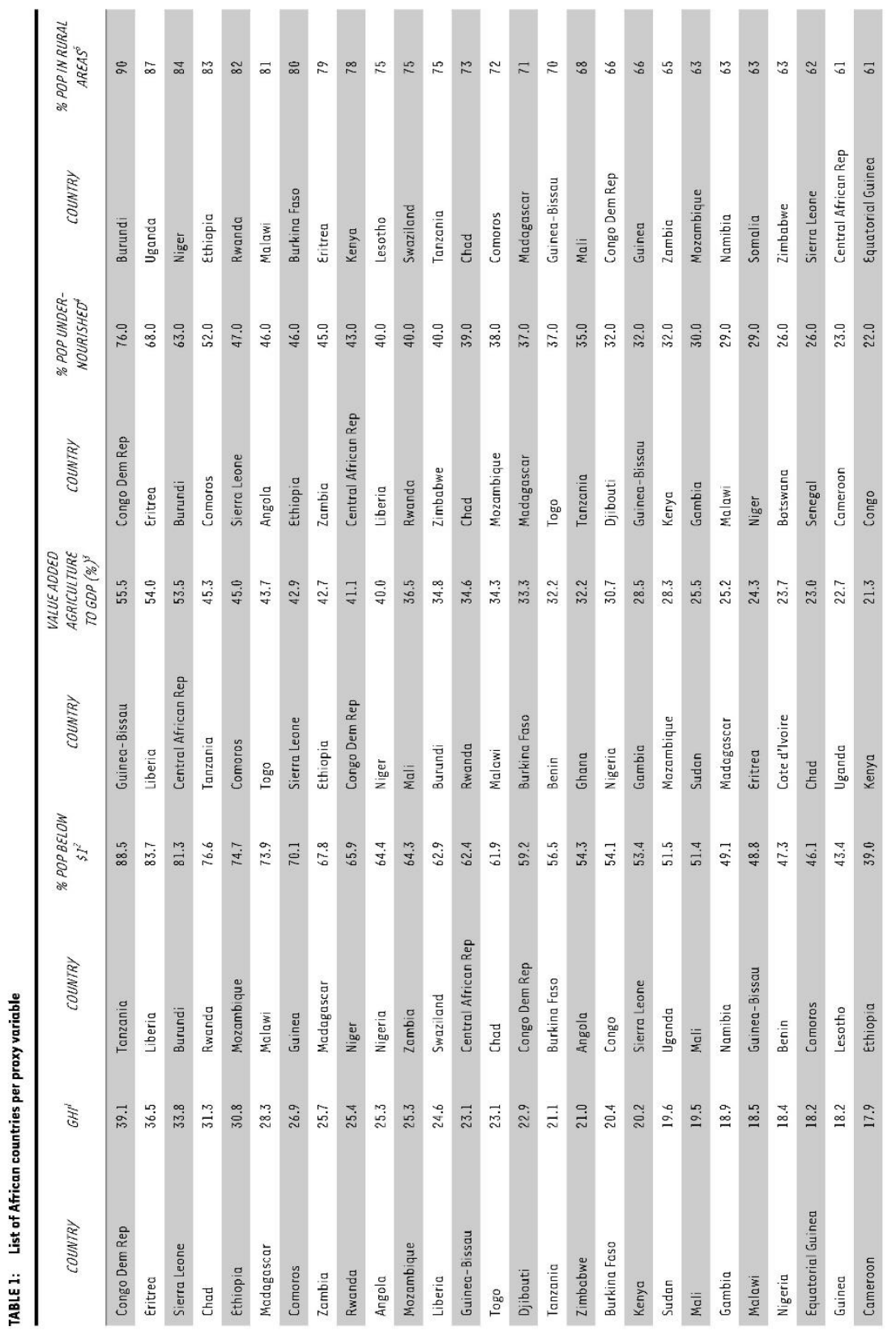




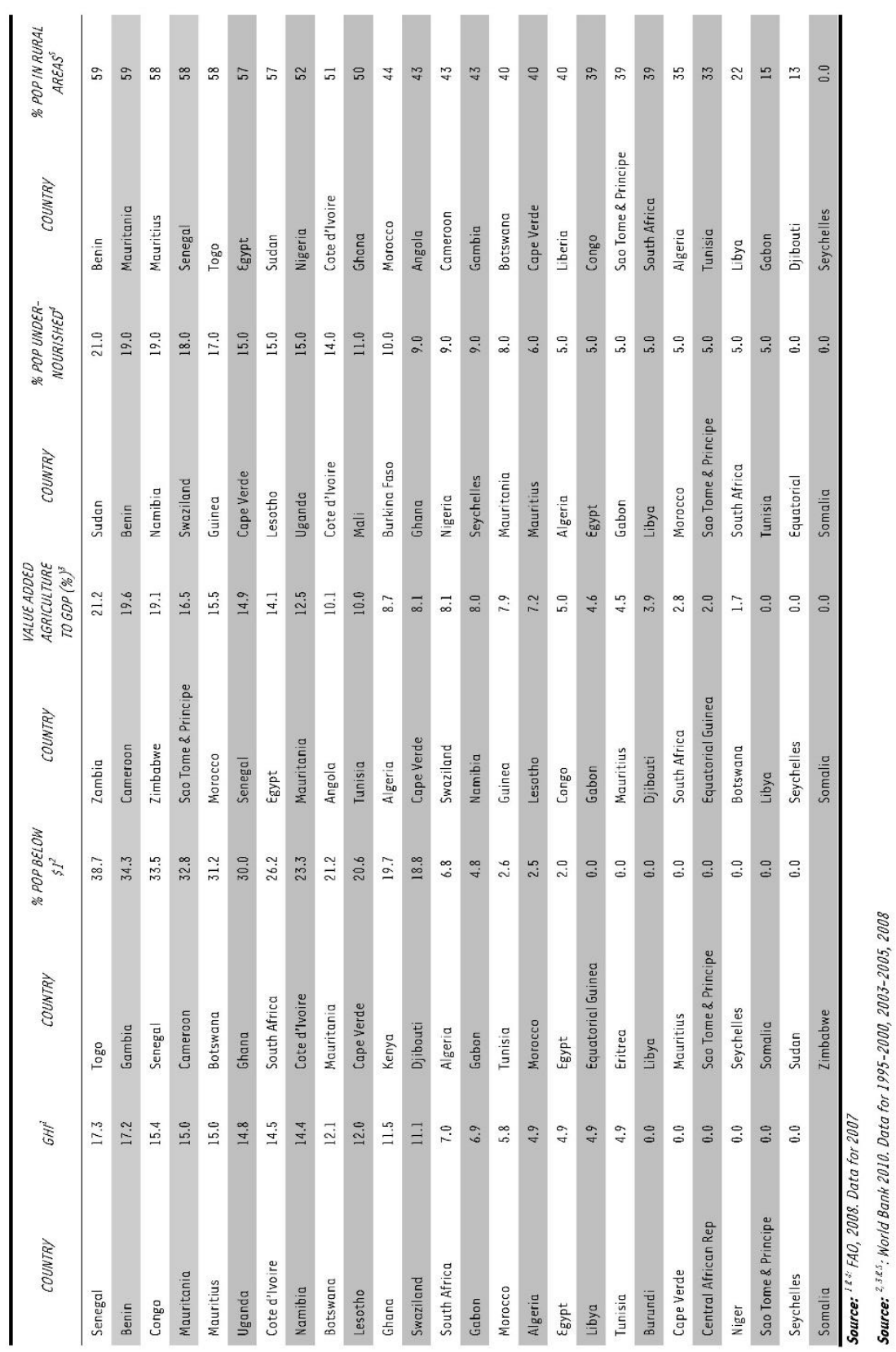




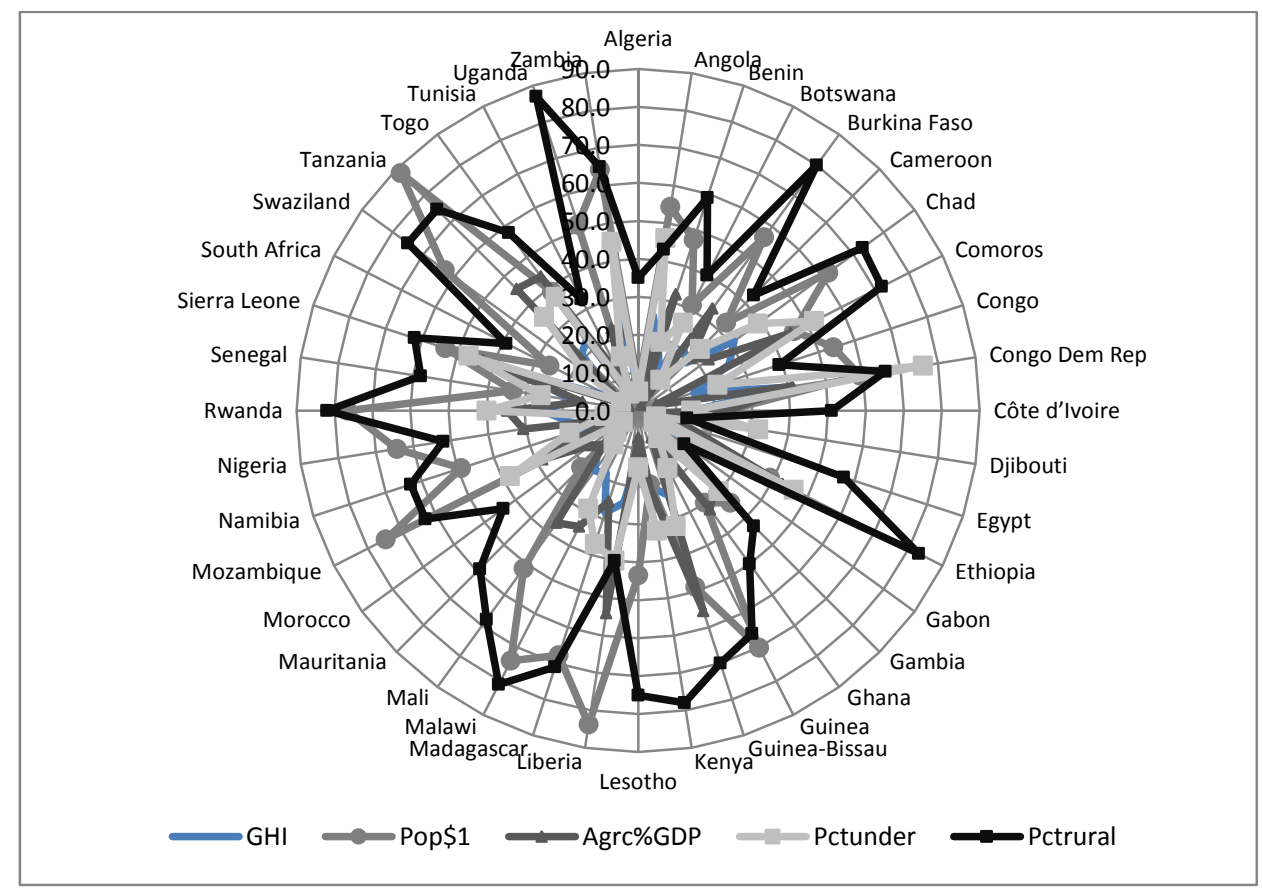

Figure 1: Summary profile of countries by indicator

Source: World Bank, 2010; FAO, 2008

To obtain a clear picture of the ranking of countries per proxy variables in TABLE 1 , a composite index was computed. This allows an examination of the risk profile of countries by region as portrayed by the composite index. The complete list of countries according to their risk profile is shown in TABLE 2 and summarised in FIGURE 2. FIGURE 2 shows the value of each country's overall index relative to a central point of zero, with values between $0 \%$ and $31.24 \%$ indicating low risk and values between $66.02 \%$ and $100 \%$ indicating high risk. As indicated earlier, the overall index for each country was the uniformly weighted sum of four indices. The indices are the percentage of the population living on less than $\$ 1$ a day, value added as a percentage to GDP by agriculture, the percentage of the population that is undernourished, and the percentage of the population living in rural areas.

FIGURE 2 and TABLE 2 show that out of a total of 44 countries, 11 are high risk, 22 are medium risk and 11 are low risk. Four countries in North Africa (Algeria, Egypt, Morocco and Tunisia) are lowrisk ones. In West Africa, only two countries (Cape Verde and Mauritania) are low risk, while the others are either medium risk or high risk. In Central Africa, the Central African Republic and Democratic Republic of Congo are high risk, while Cameroon and Chad are medium risk. In East Africa, with the exception of Djibouti, which is low risk, the others are either medium or high risk. Burundi, Comoros, Ethiopia, Malawi, Rwanda and Tanzania are all high risk. In Southern Africa, while Botswana and South Africa are low risk, others such as Lesotho, Swaziland, and Namibia are medium-risk countries. 
Lalthapersad-Pillay \& Udjo

TABLE 2: Risk profile of countries by region

\begin{tabular}{|c|c|c|c|}
\hline REGION & LOWRISK & MEDIUM RISK & HIGH RISK \\
\hline \multirow[t]{4}{*}{ NORTH AFRICA } & Algeria & & \\
\hline & Egypt & & \\
\hline & Morocco & & \\
\hline & Tunisia & & \\
\hline \multirow[t]{11}{*}{ WEST AFRICA } & Cape Verde & Benin & Guinea Bissau \\
\hline & Mauritania & Burkino Faso & Liberia \\
\hline & & Cote d'Voire & Niger \\
\hline & & Gambia & \\
\hline & & Ghana & \\
\hline & & Guinea & \\
\hline & & Mali & \\
\hline & & Nigeria & \\
\hline & & Senegal & \\
\hline & & Sierra-Leone & \\
\hline & & Togo & \\
\hline \multirow[t]{3}{*}{ CENTRAL AFRCA } & Congo & Angola & Central African Republic \\
\hline & Gabon & Cameroon & Democratic Republic of Congo \\
\hline & & Chad & \\
\hline \multirow[t]{6}{*}{ EAST AFRICA } & Djibouti & Kenya & Burundi \\
\hline & & Madagascar & Comoros \\
\hline & & Mozambique & Ethiopia \\
\hline & & Uganda & Malawi \\
\hline & & Zambia & Rwanda \\
\hline & & & Tanzania \\
\hline \multirow[t]{3}{*}{ SOUTHERN AFRICA } & Botswana & Lesotho & \\
\hline & South Africa & Swaziland & \\
\hline & & Namibia & \\
\hline
\end{tabular}

Source: Authors' analysis 


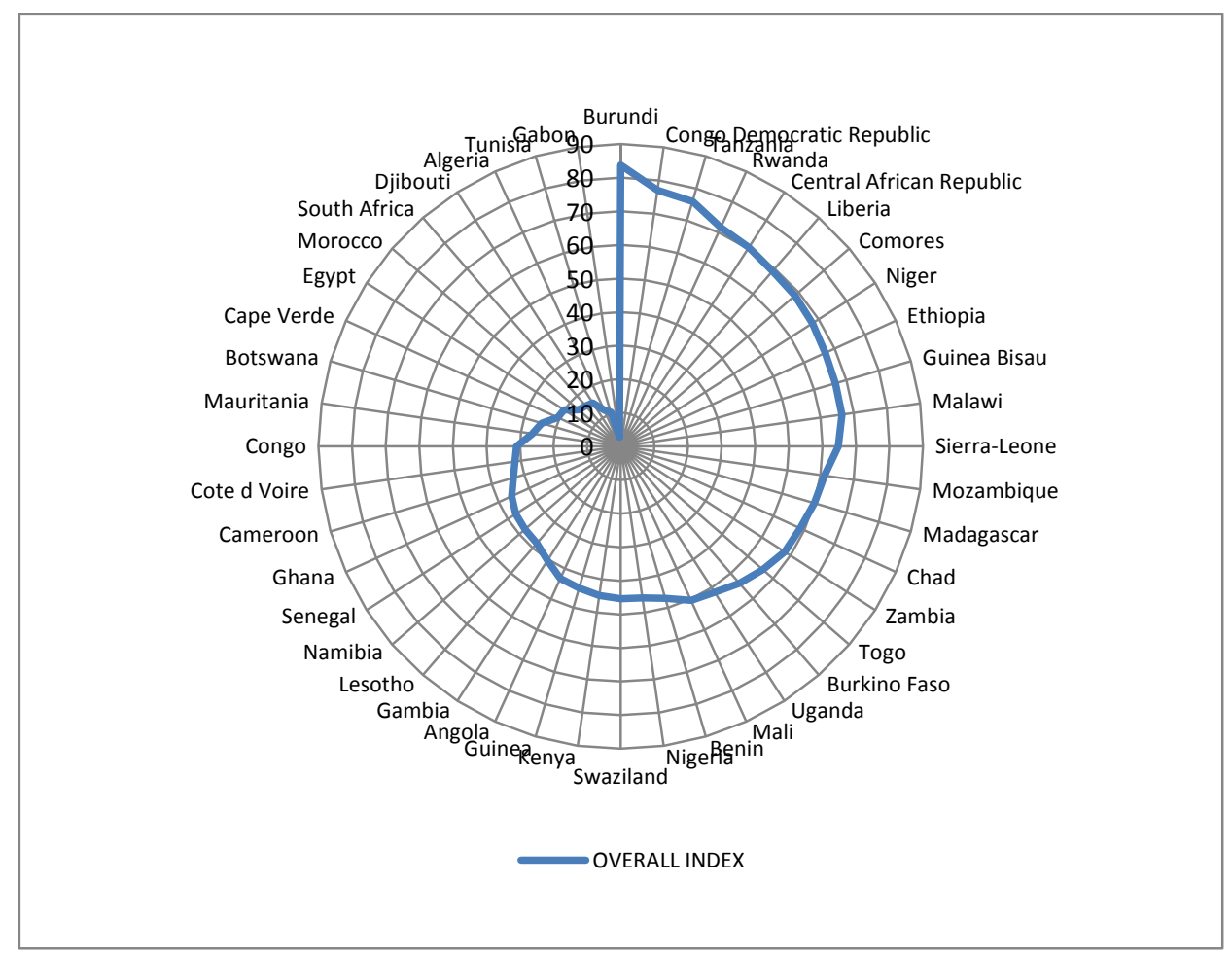

\section{Figure 2: Summary overall index profile of countries}

\section{Source: Authors'analysis}

The results in TABLE 2 are aligned with the findings in the literature on climate change that single out poverty as the factor that renders developing countries most vulnerable to climate-induced adversity (World Bank, 2010; Adger, 2006; Tol, 2010). The results show that high-risk countries have elevated levels of poverty, that is, the proportion of people living on less than US \$1 a day is above $33 \%$, and agriculture contributes in excess of one-third to GDP. Results for the same variables for low-risk countries indicate values of $20 \%$ and $5 \%$ respectively.

\section{POLICY RECOMMENDATIONS}

The eleventh Conference of the Parties (COP-11) at Montreal in 2005 reiterated the importance of both adaptation and mitigation responses to effectively deal with climate change (Sarkar, 2012). Mitigation is concerned with reining in climate change by reducing GHG emissions, while adaptation seeks to mitigate the effects of climate change. A holistic approach to arresting climate change requires the utilisation of both mitigation and adaptation measures. Sarkar (2012) recommends that adaptation interventions should complement mitigation efforts for long-term sustainability. FAO (2008) also cautions that both the adaptation and mitigation efforts are needed to avert further losses in agricultural yields. Thus far, more prominence has been afforded to mitigation but presently adaptation is now being seen as an important step. The IPCC defines adaptation as the "adjustment in natural or human systems to a new or 
changing environment" (Sarkar, 2012:524). Climate adaptation is a multifold activity that will determine how one reacts to climate variability, to limit the negative effects of climate change, to ascertain potential spinoffs that may exist and to deal with after-effects. Adaptation seeks to reduce the negative effects of climate change, and in essence comprises two aspects: coping with environmental damage, and bolstering people's ability to function under variable climates so that they can protect themselves and cope with the hazards they face. Adaptation therefore hinges on improving ecosystem management, enhancing food security and strengthening social, human capital and institutions (Sarkar, 2012).

Neither mitigation potential nor adaptive capacity is uniform across countries, people, activities, exposure and costs. Regions, countries and socio-economic groups also differ in adaptive capacity, which is always in a state of flux. Rich countries are endowed with superior mitigation potential, a population that is less vulnerable as well as greater resources for adaptation. By contrast, poor countries have lower emissions, but are more vulnerable and possess limited adaptive capacity. Moreover, those regions and communities most threatened by climate change are also the ones most susceptible, as they have low adaptive potential (Sarkar, 2012). This situation should determine the nature of climate negotiations and also the formulation of development policy. Failure to implement adaptation could push countries further into debt, which would mean continued reliance on foreign funding assistance.

The poverty in developing countries is a consequence of the livelihood patterns people adopt, which themselves entail the utilisation of climate-sensitive resources (World Bank, 2010). Interventions to reduce poverty levels and protect agriculture are paramount to countries' continued economic development. Those countries that have agriculture-based economies will have to find ways of diversifying their income sources. One method of adaptation is economic diversification, as it cushions against a loss of livelihood, inculcates economic buoyancy and lessens dependence on climate-sensitive resources, making it essential for subsistence farmers. It comprises measures to adapt existing practices to lessen exposure to risk, to implement better water management practices, to diversify the mix of crops planted and to transform the value of primary products. Diversification is advantageous, as it is more incomeyielding for the poor and helps to contain risk. Although diversification has certain shortfalls, these could be overcome by ensuring that development planning and adaptation planning are synchronised (Sarkar, 2012).

Most African countries have become food importers, but the importance of agriculture to them, even in an era of climate change, remains paramount, since Africa has enormous agricultural potential and agricultural growth is pro-poor in nature. It is also a means of mitigating rising food prices in future. Estimates by the World Bank indicate that agriculture and agribusiness will be worth a \$1 trillion in sub-Saharan Africa by 2030 - an increase from $\$ 313$ billion in 2010 . Moreover, research shows that growth from agriculture has on average been shown to be more poverty-reducing than growth from other sectors, more especially from smallholder staple crop production rather than from export crops (World Bank, 2010).

Given the importance of water resources and the possible spread of diseases, policies that seek to improve water management systems and intervention to arrest the spread of diseases such as malaria are necessary (World Bank, 2010). Recent years have seen an increasing focus on disaster risk reduction, which highlights synergies with climate change adaptation (Sarkar, 2012). Combining disaster risk reduction and climate adaptation will build resilience among vulnerable communities. Invoking climate-smart policies that enable people to deal with weather variations (for example, through the provision of flood-risk maps) would be useful. A 
study by the UN indicates that accurate flood warnings can mean up to $35 \%$ less damage (Fay, 2009; World Bank, 2010). Bangladesh is a good example of a country that is doing a lot to empower its people against climate change by putting in place localised warning systems for cyclones and flood forecasting mechanisms, as well as communication tools that utilise local and global knowledge. Addressing climate change warrants both climate-specific policies and changes to the way development policy is designed and implemented (World Bank, 2010; Sarkar, 2012). Given the interconnectedness of climate change and the economic development of countries, development policy and projects have to be structured to include both adaptation measures and climate risk management (Fay, 2009). Therefore, countries will have to allocate funding for two purposes: development and adaptation.

\section{SUMMARY AND CONCLUSION}

The article examined why climate change is a serious challenge to developing countries in general and to the African region in particular. The combination of extremely high levels of poverty and geographic fragility in developing countries makes them especially vulnerable to climate-induced adversity and may jeopardise their future economic development. The World Bank (2010:37) cautions that "development goals are threatened by climate change, with the heaviest impacts on poor countries and poor people". The results of this study, which is based on the calculation of an overall index comprising four proxy variables, shows the 11 countries in Africa are high-risk countries that will be especially vulnerable to the adverse effects of climate change.

What does climate change imply for the development agenda of developing countries and more especially for Africa? Developing countries lack financial and institutional resources to undertake adaptation measures, which poses a challenge, especially for their sustainable development. Climate change may worsen existing vulnerabilities and undo previously attained development gains. Building climate-smart interventions into development policy becomes an essential means of lowering exposure to climate threats (Sarkar, 2012). Climate change should ideally have been given more attention under Millennium Development Goal 7, which has been overlooked - something that may undermine sustainable development after 2015 (Karimov, 2013). Fay (2009) argues that by 2050 Africa's dilemma will be a larger population and shrinking food supplies, caused by a variable climate. How Africa will deal with climate change will depend on how it utilises its financial and institutional resources, and it will need to strike a balance between pursuing poverty alleviation, increasing economic growth and keeping up adaptation efforts so that further jeopardy is averted (UNECA, 2009).

\section{LIST OF REFERENCES}

Adger, W.N. (2006). Vulnerability. Global Environmental Change, 16(3), pp. 268-281.

Alderman, H., Hoddinott, J. \& Kinsey, B. (2006). Long-Term Consequences of Early Childhood Malnutrition. Oxford Economic Papers, 58(3), pp. 450-474.

Anand, S. \& Sen, A.K. (1994). Human Development Index: Methodology and Measurement. Occasional Papers. New York: Human Development Report Office. 
Brody, K., Demetriades, A. \& Esplen, દ. (2008). Gender and Climate Change: Mapping the Linkages. A Scoping Study on Knowledge and Gaps. United Kingdom: Institute of Development Studies.

Brown, 0. \& Crawford, A. (2007). Climate Change: A New Threat to Stability in West Africa? Evidence from Ghana and Burkina Faso. African Security Review, 17(3), pp. 39-57.

Campbell-Lendrum, D.H., Corvalan, C.F. \& Pruss-Ustan, A. (2003). How Much Disease Could Climate Change Cause. Geneva: World Health Organization.

Carter, M.R., Little, P.D. Mogues, T. \& Negatu, W. (2007). Poverty Traps and Natural Disasters in Ethiopia and Honduras. World Development, 35(5), pp. 835-856.

Clements, R. (2009). The Economic Cost of Climate Change in Africa. [Online] Available: http://www.christianaid.org.uk?images/economic. (Accessed 9 April 2012)

Collier, P. Conway, G. \& Venables, T. (2008). Climate Change and Africa. Oxford Review of Economic Policy, 24(2), pp. 337-353.

Confalonieri, U., Menne, B., Akhtar, R., Ebi, K.L., Hauengue, M., Kovats, R.S., Revich, B. \& Woodward, A. (2007). Human Health: Climate Change 2007: Impacts, Adaptation and Vulnerability. Contribution of Working Group II to the Fourth Assessment Report of the Intergovernmental Panel on Climate Change. Cambridge: Cambridge University Press.

Dell, M., Jones, B.F. \& Olken, B.A. (2008). Climate Change and Economic Growth: Evidence from the Last Half Century. NBER Working Paper No. 14132. Cambridge MA: National Bureau of Economic Research.

Dercon, S. (2004). Growth and Shocks: Evidence from Rural Ethiopia. Journal of Development Economics, 74(2), pp. 309-329.

Eriksen, S., O'Brien, K. \& Losentrater, L. (2008). Climate Change in Eastern and Southern Africa: Impacts, Vulnerability and Adaptation. Global Environmental Change and Human Security Report, 2.

FAO (Food and Agriculture Organisation) (2003). Conceptual Framework for National, Agricultural, Rural Development, and Food Security Strategies and Policies. Rome: FAO.

FAO (Food and Agriculture Organisation) (2008). Climate Change and Food Security: A Framework. Rome: FAO.

FAO (Food and Agriculture Organisation) (2010). Climate Change Implications for Food Security and Natural Resource Management in Africa. Twenty-sixth Regional Conference for Africa, Angola, 3-7 May 2010. Rome: FAO.

Fay, M. (2009). Africa's Development in a Changing Climate. [Online] Available: http://blogs.worldbank.org/climate.05/05/2010. (Accessed 23 May 2012)

Galor, 0. \& Weil, D.N. (1999). From Malthusian Stagnation to Modern Growth. American Economic Review, 89, pp. 150-154.

IFAD (International Fund for Agricultural Development) (2009). Support to NEPAD. Period Report July 2008 to June 2009. [Online] Available: www.un.org/Africa/ossa/2009_un_system/IFAD.PDF. (Accessed 29 March 2012).

ILO (International Labour Organization) (2008). Global Employment Trends for Women. Geneva: ILO Office. 
IPCC (Intergovernmental Panel on Climate Change) (2007). Fourth Assessment Report on Climate Change 2007: Climate Change Impacts, Adaptation and Vulnerability Summary for Policymakers. Working Group II contribution to the Intergovernmental Panel on Climate Change. Geneva.

Jensen, R. (2000). Agricultural Volatility and Investments in Children. American Economic Review, 90(2). pp. 399-404.

Kamara, A.B., Mafusire, A., Castel, V., Kurzweil, M., Vencatachellum, D. \& Plu, L. (2009). Soaring Food Prices and Africa's Vulnerability and Responses: An Update. African Development Bank. (Working Paper No.97).

Karimov. A. (2013). Positioning climate finance in the post 2015 Development agenda. [Online] Available: http://www.wider.unu.edu/publications/newsletters/articles-2013/en_GB/06-07-2013AZI (Accessed 24 June 2013).

Martorell R. \& Ho, T.J. (1984). Malnutrition, Morbidity and Mortality. Population and Development Review, 10, pp. 49-68.

Medany, M., Niang-Diop, I., Nyong, T., Tabo, R. \& Vogel, C. (2006). Background Paper on Impacts, Vulnerability and Adaptation to Climate Change in Africa. UNFCCC Convention, Ghana, 21-23 September, 2006. New York: United Nations Framework Convention on Climate Change.

Mueller, V. \& Osgood, D. (2007). Long Term Impacts of Droughts on Labour Markets in Developing Countries: Evidence from Brazil. New York: Earth Institute at Columbia University.

Niasse, M., Afoud, A. \& Amani, A. (2004). Reducing West Africa's Vulnerability to Climate Impacts on Water Resources, Wetlands and Desertification: Elements of Regional Preparedness and Adaptation. Gland, Switzerland and Cambridge: IUCN.

0’Brien, K.L., Sygna, L. \& Haugen, J.E. (2004). Vulnerable or Resilient? A Multi-scale Assessment of Climate Impacts and Vulnerability in Norway. Climatic Change, 64, pp. 193-225.

PACJA (Pan African Climate Justice Alliance). (2009). The Economic Costs of Climate Change in Africa. [Online] Available: www.christainaid.org.uk/images/economic-cost-of-climate-change-inafrica.pdf. (Accessed 8 January 2012).

Sarkar, A.N. (2012). Sustainable development through pathways of mitigation and adaptation to offset adverse climate change impacts. [Online]. Available:

http://link.springer.com/chapter/10.1007\%2F978-3-22266-5_33. (Accessed 20 April 2012).

Skoufias, E., Vinha, K. \& Conroy, H.V. 2011. The impacts of climate variability on welfare in rural Mexico. Policy Research. The World Bank. (Working Paper 5555 February 2011).

Shackleton, S.E. \& Shackleton, C.M. 2012. Linking poverty, HIV/AIDS and climate change to human and ecosystem vulnerability in southern Africa: consequences for livelihoods and sustainable ecosystem management, International Journal of Sustainable Development and World Ecology. [Online] Available: http://dx.doi.org/10.1080/13504509.2011.641039. (Accessed 12 December 2013).

Tang, K.K., Petrie, D. \& Rao, D.S.P. (2009). The Income-climate Trap of Health Development: A Comparative Analysis of African and Non-African Countries. Social Science and Medicine, 69, pp. 1099-1106.

Tol, R.S.J. (2010). The Impact of Climate Change. Perspektiven der Wirtschaftpolitik, 11(1), pp. 13-37. UNECA (United Nations Commission for Africa), (2009) Economic Report on Africa 2010. [Online] Available: http://www.uneca.org/publications/economic-report-africa-2010. (Accessed 29 January 2012). 
World Bank. (2001). Hurricane Mitch: The Gender Effects of Coping and Crises. Notes of the Development Economics Vice-Presidency and Poverty Reduction and Economic Management Network, 56, Washington, DC: World Bank.

World Bank. (2010). World Development Report. Development and Climate Change. Washington, DC: World Bank. 